School of Agriculture and Food, University of Melbourne, Melbourne, Australia

FOOD FOR THOUGHT 2020

\title{
Ultra-processed foods and the corporate capture of nutrition-an essay by Gyorgy Scrinis
}

\begin{abstract}
Food corporations have exploited the dominant model in nutrition science to shape the way their ultra-processed products are defended, promoted, and regulated. Gyorgy Scrinis examines their scientific strategies and suggests ways to reframe the debate
\end{abstract}

\section{Gyorgy Scrinis associate professor of food politics and policy}

In 2015 the New York Times revealed that Coca Cola was covertly funding the Global Energy Balance Network based at the University of Colorado, a research network set up to promote the message that all calories are equal. ${ }^{1}$ The network's aim was to show that sugar sweetened beverages are no more responsible for the rise in obesity levels than any other foods or a lack of physical activity. ${ }^{2}$ In doing so, Coca Cola was copying and adapting the corporate political activities and scientific strategies that have been pioneered and perfected by tobacco, alcohol, and drug companies to defend and promote their products. $^{34}$

Corporate food and beverage companies such as Coca Cola have engaged in what I will refer to as "corporate scientific activities.” These activities are designed to produce and influence the scientific knowledge used to evaluate, promote, legitimise, and regulate their products. Such activities include funding and conducting in-house nutrition research related to their products; sponsoring scientific seminars and expert meetings; involvement in scientific standards and policy committees; publishing in scholarly journals; funding scientific front groups; and delivering nutrition education programmes. ${ }^{2}$

Ultra-processed food corporations use these strategies not only to influence the nutritional knowledge related to their products but also to shape the broader concepts that frame scientists' and the public's understanding of food and the body. These corporations have in fact benefited from-and seek to amplify and capture-some of the methods and concepts from mainstream nutrition science. The energy balance model being promoted by Coca Cola, for example, is a standard concept used by nutrition scientists to explain weight gain and loss (ie, calories in, calories out), and which Coca Cola has attempted to appropriate and spin in a particular direction. Greater awareness of these strategies is key to recapturing the nutrition agenda and improving population health.

\section{Bias}

One common corporate scientific activity is to fund nutrition studies designed to generate favourable scientific evidence for a company's products. ${ }^{2}$ These studies have an inherent financial conflict of interest. Systematic evaluations of industry funded nutrition studies have-perhaps not surprisingly- found a funding bias effect, whereby study findings are more likely to favour the interests of their industry sponsors. ${ }^{2}$

However, food corporations are also able to influence nutrition research through the types of nutrition studies they choose not to fund, producing what we might call "not funding" bias. Manufacturers of ultra-processed foods have had little interest in funding research that measures the detrimental effects of their products, and this may partly explain the neglect of such research over the past 50 years.

At the same time, these manufacturers have benefited from-and promoted and amplified-nutritionism, a reductive scientific methodology that favours the fragmented and isolated analysis of single foods and single nutrients out of the context of the foods and dietary patterns in which they're consumed. ${ }^{5}$ This approach has diverted attention from the study of the ingredients, additives, and processing techniques used in the manufacture of ultra-processed foods, and from the study of such products as a whole, including the dietary patterns they produce. It has also obscured the broader social, commercial, and ecological determinants of dietary health. This model has a methodological and agenda setting bias that has consistently worked in the interests of food corporations. $^{6}$

\section{Defining harm reduction}

Within this nutrient centric model, any health harms associated with ultra-processed foods are primarily attributed to their typically high concentration of particular nutrients (sodium, sugars, saturated and trans fats, etc) or energy density. In framing the harms of ultra-processed foods in this way, the solution is similarly framed as the nutritional reformulation of these products to reduce the levels of some of these nutrients. While the minimal reductions in sugars and sodium achieved are welcome, this nutrient focus distracts from the effects of the highly processed, deconstituted, and chemically transformed ingredients and additives that these products are typically constructed from (box 1).

\section{Box 1: What are ultra-processed foods?}

Ultra-processed foods and beverages can be defined as products with additives and industrially processed ingredients that have been technologically broken down 
and modified. 7 They are not merely processed foods with high levels of sugar, salt, and fat but also contain ingredients and additives not commonly used in home kitchens and artisanal restaurants, such as synthetic flavours, emulsifiers, hydrogenated oils, and soy protein isolates. The role of these ingredients is often to simulate the taste, texture, or nutritional profile of minimally processed foods.

Ultra-processed products now account for nearly half of the average dietary intake of some high income countries, with consumption rising rapidly in most other countries. Studies conducted within several countries have found that higher intake of these products is associated with the increased incidence of obesity and some chronic diseases. In low and middle income countries, these products may also be contributing to multiple forms of malnutrition.

While research is still in its relatively early stages, the health effects of ultra-processed foods may be due to a combination of the nutrients and processed ingredients these products contain and the types of ingredients and foods they displace. These products are a major contributor to poor quality dietary patterns, characterised by excessive intake of nutrients and foods such as sugar, salt, refined grains, and processed meats and relatively deficient in fibre and some micronutrients. ${ }^{8}$ They are also designed to be easily and quickly consumed, promoting overconsumption.

The sugar, salt, and fats (as well as the additives) are in fact added to these products to mask and give flavour and texture to otherwise technologically degraded foods, and to simulate the taste of minimally processed foods and dishes. This is also why these companies are having difficulties removing sugar and salt from their products, and why these ingredients need to be replaced with other synthetic sweeteners and flavouring and texturing agents.

Even though Coca Cola has for many years been attempting to manufacture doubt about the harms of sugar, the company, along with other corporations, has come to accept the necessity of nutrient reductions as a means of providing political and scientific legitimacy for its products. This is partly because companies fear the prospect of government regulations that would require either the reduced consumption of their products, or a more substantial improvement in their quality. ${ }^{9}$

Corporations such as Unilever, Nestlé, and Mars have instead developed their own nutrient profiling systems that set industry friendly technical standards for voluntary nutritional reformulation and are clearly hoping to deter independently developed and mandatory nutritional standards. Nestlé has also attempted to lend scientific credibility to its in-house nutrient profiling system-an example of the scientific strategy of credibility engineering-by publishing studies in academic journals to show the scientific legitimacy of its system. ${ }^{10}$

\section{Imagined health benefits}

Nutritionism has provided a framework through which food corporations can market the nutritional and health benefits of their products. ${ }^{11}$ While nutrition scientists and public health nutritionists have shifted their focus from nutrients to foods, dietary patterns, food environments, and ecological contexts, food corporations have stepped up to become the primary promoters and defenders of this nutrient centric model. They do so partly through the weight of their scientific research and marketing activities that focus on single nutrients or single ingredients, and that continually direct and maintain the public's attention on these nutrients and food components.

Unlike drug corporations, food manufacturers do not need to make explicit health or disease prevention claims on their food labels to communicate health benefits to consumers. Food companies can instead rely on simple nutrient and ingredient claims on their products - such as "high" in protein, fibre, omega 3 fats, or antioxidants-which then function as implied health claims. These claims are intended to produce what we may call "imagined health benefits," whereby consumers form a link between particular food components and their health benefits. One of the aims of nutritional marketing is to populate the imaginations of consumers so as to create nutritional halos around commercial products.

Importantly, food labelling regulations in most countries facilitate and are complicit with these implied health claims by permitting the use of nutrient content claims on most ultra-processed foods, regardless of the overall nutritional quality of the products.

Food corporations also attempt to commodify and capture the latest nutritional advances around which there is much promise and hype, such as the microbiome, plant based meat alternatives, functional and medicinal foods, and personalised nutrition. They piggyback on the promissory claims of emerging scientific innovations and trends in nutrition. Nestlé, for example, has published scientific research claiming that some heat treated (ie, dead) probiotic bacteria can provide greater gut health benefits than live bacteria, thereby paving the way for it to apply for an approved probiotic health claim on its longlife packaged products. ${ }^{12}$

\section{Framing the body's nutritional requirements}

Food corporations shape the scientific evidence and understanding of the body's nutritional needs-and of diet related conditions and diseases-to position their products as solutions to these health problems. This includes shaping expert understanding of the prevalence, severity, and causes of diet related conditions such as obesity and micronutrient deficiencies, as well as the nutritional needs of infants. This is akin to the "disease mongering" that drug corporations are accused of. ${ }^{13}$

Infant and child feeding is an area in which formula milk companies have heavily invested in primary scientific research, education, and outreach. For example, Nestlé funds research, seminars, and publications on the "first 1000 days" of an infant's life. These emphasise the importance of-and may generate anxieties and calls for intervention into-the three year window from conception to 2 years of age. ${ }^{14}$ At the same time, Nestlé conducts and funds research into breastmilk composition to inform the development and marketing of its infant formula and follow-on products for toddlers. ${ }^{15}$ Its marketing implies-and allows parents to imagine-that these products are the equivalent of or better than breastmilk or home prepared foods, with mothers made to feel anxious about the quality of their breastmilk.

Food corporations exploit the conventional scientific framing of micronutrient deficiencies as distinct conditions that are caused-and able to be solved-by the absence or addition of single, isolated micronutrients. ${ }^{16}$ Manufacturers have been aggressively marketing cheap, micronutrient fortified, ultra-processed foods in low and middle income countries as a solution to this form of malnutrition. This is a strategy for expanding sales in poor communities in these countries. At the same time, these corporations sponsor scientific meetings on specific micronutrient deficiencies targeted at experts, and they organise nutrition education campaigns in vulnerable communities to teach people about the risks of, and solutions to, their micronutrient deficiencies.

\section{Recapturing nutrition science}

The corporate capture of nutrition-while far from comprehensive or complete-is a result of the integration of various corporate scientific activities and nutritional strategies, supported and amplified by marketing and political activities. To counter this 
influence requires mitigating and undermining all these forms of corporate power.

Various strategies have been proposed or implemented, typically calling for greater transparency and independence of scientists, research funding, scholarly publications, and expert committees. They include proper disclosure of conflicts of interest in journal publications and for decision making committees; the refusal of industry funding and sponsorships by university scientists and professional associations; and the exclusion of industry funded studies from dietary guideline reviews. ${ }^{17}$

Given the central role of labelling and marketing in corporate scientific strategies, recent government initiatives on food labelling and marketing in countries such as Chile and Mexico could go further still, disallowing all types of nutrient, ingredient, and health claims and restricting the marketing and availability of all ultra-processed products.

Current policies and regulations are still primarily focused on single and isolated nutrients or ingredients, and on individual products and practices of food corporations. But given that these corporations are the primary manufacturers of ultra-processed foods, we need to shift the regulatory focus to the entire ultra-processed food category, and to regulate the entire product portfolios of these corporations.

It is also important to continue to develop less reductive and more integrated dietary frameworks to underpin the research into, and regulation of, ultra-processed foods and food corporations. The challenge is not only to understand the role of the various dietary dimensions that mediate health (ie, nutrients, foods, and dietary patterns) but also to account for the role of social, commercial, and ecological determinants of health.

Such frameworks will contribute to the project of reimagining food systems that aim to provide nourishing, convenient, and minimally processed foods, and in which the harmful products and practices of ultra-processed corporations are no longer tolerated. ${ }^{18}$

\section{Biography \\ Gyorgy Scrinis is associate professor of food politics and policy in the School of Agriculture and Food at the University of Melbourne. His research draws on the philosophy and sociology of science and technology, social theory, agri-food studies, and public health nutrition. He has published on the philosophy of nutrition science, the health effects of ultra-processed foods, bias in nutrition research, corporate power, the nutritional engineering and marketing strategies of food manufacturing corporations, food labelling, animal welfare and agricultural technologies. His book Nutritionism: The Science and Politics of Dietary Advice (2013) explores the history and consequences of the reductive focus on nutrients in nutrition science and dietary guidelines.}

Competing interests: I have read and understood BMJ policy on declaration of interests and have no relevant interests to declare.

Provenance and peer review: Commissioned; externally peer reviewed.

This article is part of a series commissioned by The BMJ. Open access fees were paid by Swiss Re, which had no input into the commissioning or peer review of the articles. The BM/ thanks the series advisers, Nita Forouhi, Dariush Mozaffarian, and Ann Lartey for valuable advice and guiding selection of topics in the series.

1 O'Connor A. Coca-Cola funds scientists who shift blame for obesity away from bad diets. New York Times 2015 Aug 9

https://wellblogsnytimes.com/2015/08/09/cocacolafunds-scientists-who-shift-blamefor-obesity-away-from-bad-diets/

2 Nestle M. Unsavory truth: how food companies skew the science of what we eat. Basic Books, 2018.

3 White J, Bero LA. Corporate manipulation of research: strategies are similar across five industries. Stan Law Policy Rev 2010;21:105.
4 Mialon M, Julia C, Hercberg S. The policy dystopia model adapted to the food industry: the example of the Nutri-Score saga in France. World Nutrition

2018;9:109-20doi: 10.26596/wn.201892109-120

5 Scrinis G. Nutritionism: The Science and Politics of Dietary Advice. Columbia University Press, 2013. doi: $10.7312 /$ scri15656

6 Fabbri A, Chartres N, Scrinis G, Bero LA. Study sponsorship and the nutrition research agenda: analysis of randomized controlled trials included in systematic reviews of nutrition interventions to address obesity. Public Health Nutr 2017;20:1306-13. doi: 10.1017/S1368980016003128 pmid: 27989264

7 Monteiro CA, Cannon G, Moubarac JC, Levy RB, Louzada MLC, Jaime PC. The UN Decade of Nutrition, the NOVA food classification and the trouble with ultra-processing. Public Health Nutr 2018;21:5-17. doi: 10.1017/S1368980017000234 pmid: 28322183

8 Monteiro CA, Cannon G, Lawrence M, etal. Ultra-processed foods, diet quality, and health using the NOVA classification system. FAO, 2019

9 Scrinis G, Monteiro CA. Ultra-processed foods and the limits of product reformulation. Public Health Nutr 2018;21:247-52. doi: 10.1017/S1368980017001392 pmid: 28703086

10 Vlassopoulos A, Masset G, Charles VR, etal. A nutrient profiling system for the (re)formulation of a global food and beverage portfolio. Eur J Nutr 2017;56:1105-22.doi: 10.1007/s00394-016-1161-9 pmid: 26879847

11 Scrinis G. Reformulation, fortification and functionalization: big food corporations' nutritional engineering and marketing strategies. J Peasant Stud 2016;43:17-37. doi: 10.1080/03066150.2015.1101455

12 Nestlé. Probiotic foods that give a better gut feeling? 2015. https://www.nestle.com/media/news/nestle-scientists-heat-treated-probiotics-foods

13 Moynihan R, Cassels A. Selling sickness: how the world's biggest pharmacetical companies are turning us all into patients. Nation Books, 2005.

14 Bee J, Diby P, Mbacké B, etal. Nestlé: sustainable value chain management from the farm to the fork. In: D’heur M, ed. Sustainable value chain management. Springer, 2015: 313-25doi: 10.1007/978-3-319-12142-0_14

15 Tanrikulu H, Neri D, Robertson A, Mialon M. Corporate political activity of the baby food industry: the example of Nestlé in the United States of America. Int Breastfeed J 2020;15:22. doi: 10.1186/s13006-020-00268-x pmid: 32268902

16 Scrinis G. Reframing malnutrition in all its forms: a critique of the tripartite classification of malnutrition. Glob Food Secur 2020;26:100396.doi: 10.1016/j.gfs.2020.100396.

17 Moynihan R, Bero L, Hill S, etal. Pathways to independence: towards producing and using trustworthy evidence. BMJ 2019;367:16576. doi: 10.1136/bmj.16576 pmid: 31796508

18 Adams J, Hofman K, Moubarac JC, Thow AM. Public health response to ultra-processed food and drinks. BMJ2020;369:m2391. doi: 10.1136/bmi.m2391 pmid: 32591348

This is an Open Access article distributed in accordance with the Creative Commons Attribution Non Commercial (CC BY-NC 4.0) license, which permits others to distribute, remix, adapt, build upon this work non-commercially, and license their derivative works on different terms, provided the original work is properly cited and the use is non-commercial. See: http://creativecommons.org/licenses/by$\mathrm{nc} / 4.0 \%$. 